\title{
OVERVIEW OF GENERETOR PROTECTION ON POWER SYSTEM
}

\author{
Ms. Seada Hussen \\ Department of Electrical and \\ Computer Engineering \\ Addis Ababa Science and \\ Technology University \\ Addis Ababa, Ethiopia
}

\author{
Ms. Frie Ayalew \\ Department of Electrical and \\ Computer Engineering \\ Addis Ababa Science and \\ Technology University \\ Addis Ababa, Ethiopia
}

\author{
Dr. Gopi Krishna Pasam \\ Department of Electrical and \\ Computer Engineering \\ Addis Ababa Science and \\ Technology University \\ Addis Ababa, Ethiopia
}

\begin{abstract}
$A B S T R A C T$ - Generators are the majority source of commercial electrical energy and the most essential and expensive elements in power industry since, it is difficult to replace. It need to protect either by using electrical or mechanical protection devices before any failure is happen on those equipment's since, protecting equipment's from any failure can improve reliability of the system, minimize operating cost and minimize energy or power loss. Under this paper different types of fault on generator such as stator fault, rotor fault and abnormal condition of generator, protection techniques based on (Change in load current, Stator temperature and resistance and Rotor speed) for those faults on generator, protection devices (relay, instrument transformer, circuit breaker and so on), optimization techniques are discussed in detailed and observation and gap seen from the paper, conclusion and recommendation for future researchers are indicated .
\end{abstract}

Keywords: Abnormal condition of generator, Rotor fault, Stator fault, Protection techniques, Protection devices, Optimization techniques.

\section{INTRODUCTION}

In power system electrical equipment like transformer and generator requires Protective devices, instrumentation and controls which can prevent or limit electrical damage to those materials. The protective device warns of unsafe or abnormal conditions, or automatically reacts to such conditions. Many researchers have demonstrated the concepts of protection for generator in power system by using different methods. Pedro Nunes.et al (2003) identifies cause of malfunction of generator and mitigation techniques simulate it by using EMTP, resulted in establishing the link between the transformer inrush current phenomenon and the generator differential protection mal-functioning. Prafulla Pillai.et al. (2003) doing stator ground failure and theoretical basis was done in previes work, this part various grounding method in industrial application. Z. Bukhala S.et al. (2007) prepares the guidance for better coordination with generator protection with generator control. Michael J. Thompson (2012) Synchronize a generator to reduce cost, improve reliability, and easily accomplish complete integration, automation, and remote control of the system. Michael J. Thompson (2012) presents synchronizing method to adjust frequency and voltage to the incoming generator this can made either manually, automatic or combination of both

N. G. Chothani.et al. (2014) use a method to isolate generator from the system when fault is happen on the system by using a multifunction numerical relay (MiCom P341) which is used to provide protection from overload/overcurrent, over/under, voltage, over/under frequency and restricted earth fault (REF) protection which are employed in actual field. H. Balaga.et al.(2015) are presents use of artificial neural network for the combined differential protection of generator-transformer unit with an aim to build a backup protection system to improve the overall reliability of the system since, transformer and generator are simulated using matlab/Simulink. M V Sudhakar.et al. Nidhi Verma.et al. (2015) implement circuit offers minimal delay time which enables better time response for Protection solid state relays for enhancement of power system protection. M V Sudhakar.et al.(2017) presents a protection scheme which considers Turbine, generator and its excitation as dynamic sources and consider over-flux protection scheme of generator and simulate the function using Matlab. 
Magdi El-Saadawi.et al.(2017) propose a new method for fault detection and classification based support vector machine compared and with artificial neural network. Mehulkumar D. Devdhariya.et al. (2017) presents relay coordination to achieve selectivity and speed without sacrificing sensitivity and fast fault clearance time and the current setting of relays are known prior and then find the time multiplier setting (TMS) of the relays For optimal relay co-ordination. Arathi Premnath.et al. (2017) introduces a method to reduce fault current by using resistive type SFCL and simulation is done by Matlab/Simulink. S.Elango.et al. (2018) design microcontroller to chalk only current level of transformer and isolate power transformer from distribution line if there is a fault. J.K. Wang.et al. (2018) propose method contains two objectives, minimum delay of backup protective devices and maximum DGs' total output power and use an algorithm to solve optimization problem arising from nonlinearity of recloser/relays' TCI inverse curves.

Priti T. Indurkar.et al.(2018) presents about generic relay which is a lumped all conventional relay for the control of any overload voltage or current and protection of the devices from these parameter and constantly monitor the parameter to be controlled and if it exceeds the percentage range. This relay combined with knowledge based method it becomes intelligent. Lee et al.(2002) presented instantaneous overcurrent relay and a reverse power relay operation using hardware and software. Frie Ayalew. et al (2018) presents about an overview of application area of optimization techniques such as mathematical optimization methods those are Unconstrained optimization approaches Nonlinear programming (NLP), Linear programming (LP), Quadratic programming $(\mathrm{QP})$, Generalized reduced gradient method, Newton method, Network flow programming (NFP), Mixed-integer programming (MIP), Interior point (IP) methods and Artificial intelligence used in power system.

\section{OVERVIEW OF GENERATOR PROTECTION}

Electrical power systems experience faults at various times due to various reasons those faults must be Foreseen and safety precautions applied to the power system [15]. Protection devices are selected by depending on the rating of type of generators and equipments. Such as synchronous generator, DC generator, Rheostats ( for controlling various parameters), Instrument Transformers, Relay, Circuit Breaker and so on. Generator protection includes many elements to detect abnormal operating conditions so that the generator and mechanical systems can be tripped before damage can occur. Two of the abnormal operating condition protective elements associated with synchronizing problems are reverse power/antimotoring and underexcitation/loss-of-field protection [4]. Protection systems of generator are listed in Fig 2 and inadditon to those relays, Loss of excitation protection, Differential protection[36], Rotor earth fault protection. Reverse power protection, Sequence current protections are used for generator protection. Different type of faults and protection devices of those faults are discussed below.

\section{[A]. Different fault types on generator}

An electrical generator can be subjected to either an internal fault or external fault or both. The generators are normally connected to an electrical power system, hence any fault occured in the power system should also be cleared from the generator as soon as possible otherwise it may create permanent damage in the generator. Many types of faults occur due to the insulation breakdown of the stator coils [38]. Phase to phase faults and inter-turn faults are less common and these are developed into earth faults but interturn faults are difficult to be detected, Rotor Faults and abnormal operating condition of generator. But a generator has to be protected not only from electrical faults (stator and rotor faults) and mechanical problems (e.g. Related to turbine, boilers etc), but it also has to be protected from adverse system interaction arising if generator going of out of step with the rest of system, loss of field winding etc. Under certain situations like internal faults, the generator has to be quickly isolated (shut down), while problems like loss of field problem requires an 'alarm' to alert the operator. Following is a descriptive list of internal faults (or stator and rotor faults) and abnormal operating conditions (Fig 1) $[9,17]$. 


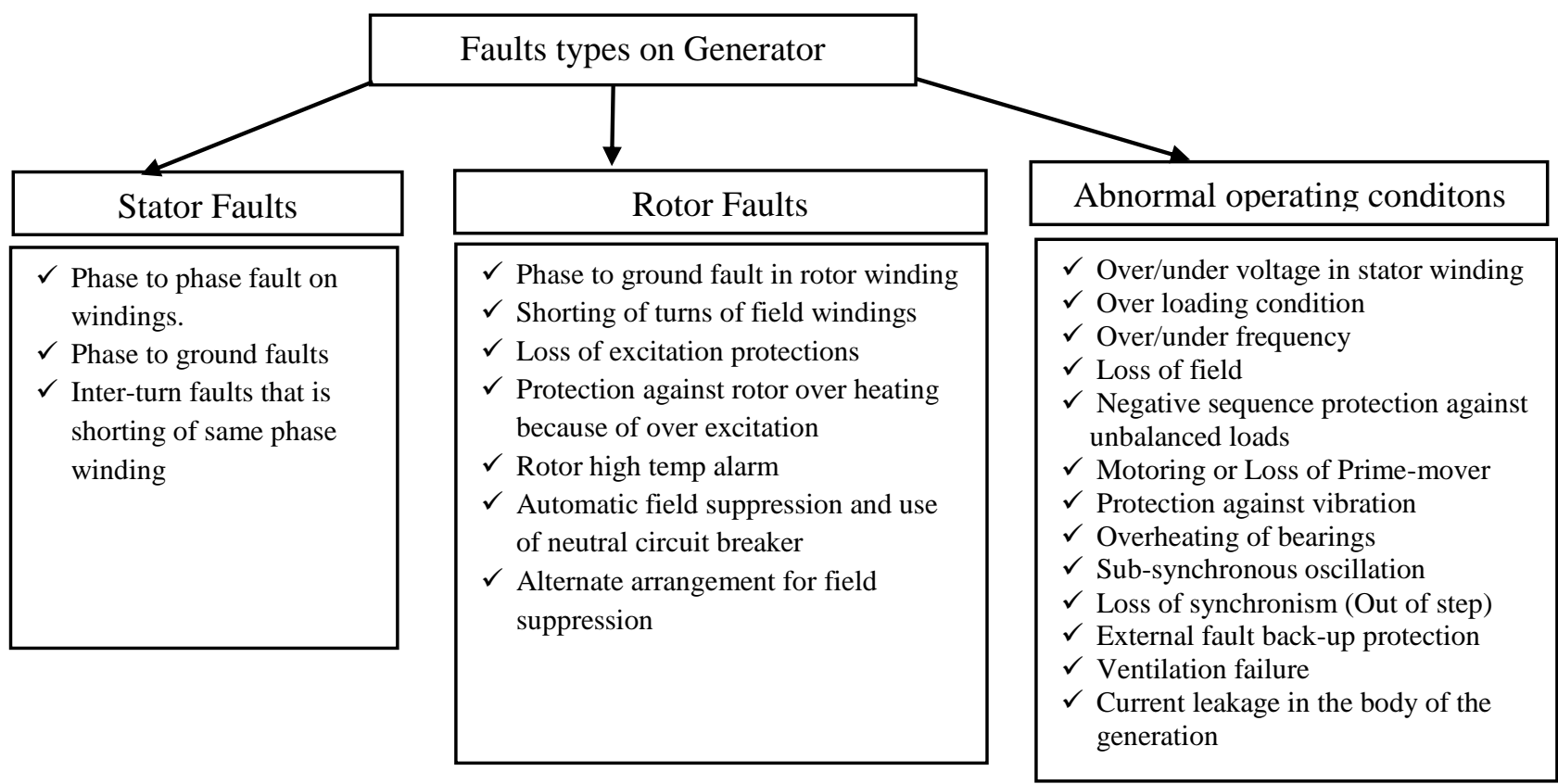

Fig 2: Faults types on generator and related papers[9][17][32]

\section{[B]. Different types of protection system on generator}

Generator Protection [39] Schemes are particular groupings of various protections of generator. These classes are actually based on three factors: Change in load current, Stator temperature and resistance and Rotor speed [26]. There are so many protection systems on generators among them the most common one is

$>$ Overload \& Overcurrent Protection: arise due to excessive load on the system, overcurrent condition and due to occurrence of fault (i.e. insulation failure, etc.) [5, 40].

$>$ Overvoltage \& Under voltage Protection:

$>$ Restricted Earth Fault Protection (REF): current difference which used to operate the relay successfully when an internal fault occurs due to failure of insulation of any phase winding connecting current transformer is better to identify the status of current [5].

$>$ Over frequency \& under frequency: over frequency happen due to outage of large load then it can be controlled by reducing the current either through field or armature and simulate over frequency in isolated system is to cut out a heavy load from the system. But under frequency happen due to sudden fall of heavy load on generator, the generator delivers larger current and the frequency of the system drops this can be reduced by decreasing resistance of field and armature rheostat of DC motor. Another way of simulating this condition is by overloading the system [5].

$>$ Over fluxing protection: which is mean that per unit voltage divided by per unit frequency and caused by different reasons such as over speeding of turbine, Load rejection on machine due to tripping a block of load, AVR malfunctioning in machine operating condition, Over excitation during machine off load condition, When machine runs at higher terminal voltage than rated and When machine runs at rated /less then rated voltage with lower frequency. It can be protect by use a relay which measures the ratio between voltage and frequency $(\mathrm{V} / \mathrm{Hz}$ relay), reduced speed, voltage produced by it is proportionately and soon[9][26].

The various forms of protection applied to the generator can be categorized in to two manners: 
1. Protective relays to detect faults occurring outside the generator

2. Protective relays to detect faults occuring inside the genrator

\section{Protective Relays}

The protective relays are used to protect the generator faults before damaging it, either the faults are occuring inside or outside the generator. Other than protective relays, associated directly with the generator and its associated transformers, there are lightning arrestors, over speed safe guards, oil flow devices and temprature measuring devices for shaft bearing, stator winding, transformer winding and transformer oil etc. Some of these protective arrangement are of non trip type i.e. They only generate alarm during abnormalities. The other protective relays used for generator protection is listed in Fig 2:

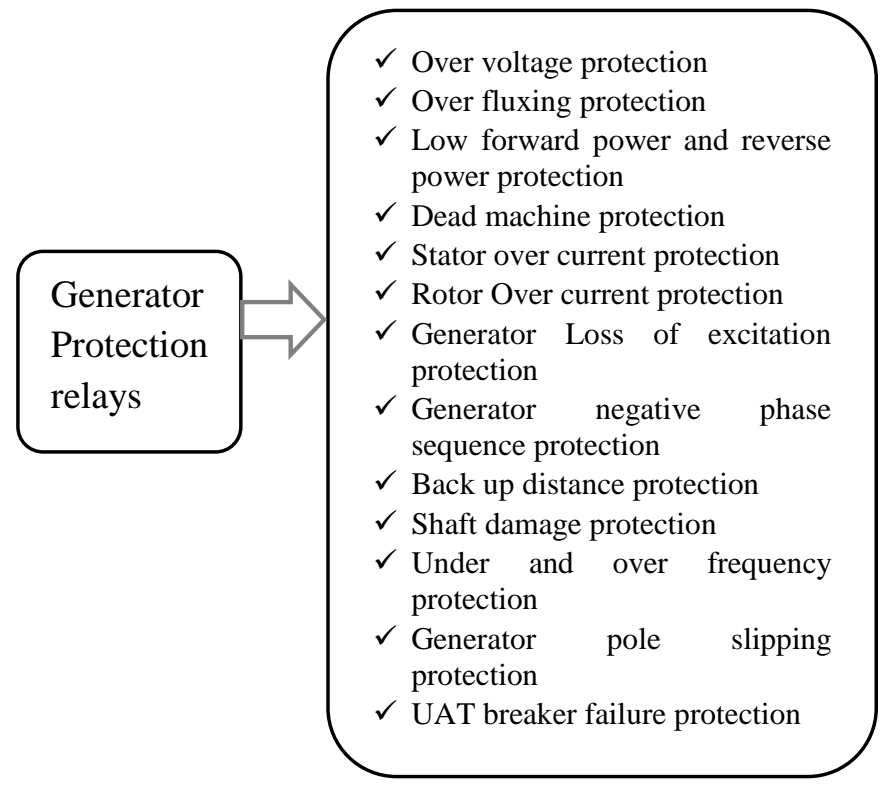

Fig 1: Generator protection relays[36]

\section{OVERVIEW OF OPTIMIZATION TECHINIQUES IN GENERETOR PROTECTION}

Many optimization techniques were implemented as fault classifier such as ANN-based algorithms his one of the method which has been successfully implemented in many pattern or signature recognition problems, as they can detect the normal operation of generator and transformer by recognizing their wave shapes, more precisely and differentiating them from the fault current wave shapes [23]-[25][33-35]. Genetic algorithm doesn't require derivative information for optimization, and its better based on the principles of genetics [6].and others methods such as Traditional techniques (Weighting Objectives, Goal programming, Constraint programming, Stochastic, Linear Programming, Gradient Based/Hill Climbing, Sequential Optimization, etc.), AI solutions (Evolutionary Computation, Particle swarm optimization, Fuzzy Set Theory, Ant colony search algorithm, Simulated Annealing, Pareto multi objective Optimization) are used in power system operation and control[28-30].

\section{OBSERVATION}

The earth fault is limited by the resistance of the neural earthing. When the fault occurs near the neutral point, this causes a small current to flow through the operating coil and it is further reduced by the neutral resistance [20].

$>$ Faulty synchronizing can damage the electrical and mechanical generating system, cause disturbances to the power system, and cause the unit to trip offline [4].

$>$ "Differential relays which uses restraint and blocking differential elements in parallel operate faster than differential relays that use only one differential element"[16].

$>$ Negative sequence filter provided with the over current relay is used for the protection against unbalance loading[17].

$>$ To improve manual and automatic synchronizing system use protective-relay-grade microprocessor devices [4].

Differences of each optimization techniques are characterized by the time spent for the prototyping, the robustness in industrial environment [28].

$>$ To keep the generator in safe condition dynamic control of real and reactive power using FACT devices is important but controlling its impact is also mandatory [31,37].

$>$ Generator maintenance scheduling is used to improve power system reliability and protecting the system [29]. 
International Journal of Engineering Applied Sciences and Technology, 2019

Vol. 3, Issue 11, ISSN No. 2455-2143, Pages 12-18

Published Online March 2019 in IJEAST (http://www.ijeast.com)

\section{CONCLUSION AND RECOMMENDATION}

\section{[A]. Conclusion}

Synchronous Generators are the majority source of commercial electrical energy (SGs). The failure of SGs causes severe damage to the machine, interruption of electrical supply, and ensuing economic loss. There is a need to provide that kind of requirements for the short circuit protection scheme, which ensure fast and selective elimination of faults. The operational range can be determined based on the specific protection scheme plus a margin instead determining generator fault clearing time. Identifying the fault type ether it is rotor type, stator type or abnormal operating condition of generator and way of mitigation is necessary for generator protection. Also using optimization techniques on the system is important for cost minimization.

\section{[B]. Recommendation}

$>$ Support vector machine compared with artificial neural network in generator protection scheme gives faster response and better reliability for fault classification.

$>$ It is recommended that microcontroller based transformer protection achieves Fast response, Better isolation, Accurate detection of the fault.

> Solid state relay has high degree of reliability, shock and vibration resistant, fast response and microprocessor compatibility.

$>$ It is necessary to the active or reactive power limits of a generator shall be restricted in order to guarantee proper fault clearing if necessary.

\section{REFERENCES}

[1] Pedro Nunes, Atef Morched, M. Teresa Correia de Barros(2003). Analysis of Generator Tripping Incidents on Energizing Nearby Transformers, International Conference on Power Systems Transients - IPST 2003 in New Orleans, USA.

[2] Prafulla Pillai, Alan Pierce, Bruce Bailey, Bruce Douglas, Charles Mozina, Clifford Normand, Daniel Love, David Shipp, Gerald Dalke, James R. Jones, Jay Fischer, Jim Bowen, Lorraine Padden, Louie Powell, Neil Nichols, Ralph Young, Norman T.Stringer (2003). Grounding and Ground Fault Protection of Multiple Generator Installations on Medium-Voltage Industrial and Commercial Power Systems, Presented at the 2003 IEEE IAS Pulp and Paper Industry Conference in Charleston.
[3] Z. Bukhala S. Conrad, T. Crawley, J. Gardell, R. Hamilton, I. Hasenwinkle, D. Herbst, L.Henriksen, G. Johnson, P. Kerrigan, S. Khan, G. Kobet, P. Kumar, S. Patel, B. Nelson, D. Sevcik, M.Thompson, J. Uchiyama, S. Usman, P. Waudby, M. Yalla(2007). Coordination of Generator Protection with Generator Excitation Control and Generator Capability, IEEE Power engineering society general meeting.

[4] Michael J. Thompson (2012). Fundamentals and Advancements in Generator Synchronizing Systems, SEL Journal of Reliable Power, Volume 3, Number 1.

[5] N. G. Chothani, A. K. Desai, M. B. Raichura and A. S. Chaturvedi(2014). Development of Generator Protection using Multifunction Numerical Relay in Laboratory, International Journal of Advanced Research in Electrical, Electronics and Instrumentation Engineering (An ISO 3297: 2007 Certified Organization) Vol. 3, Issue 4, April 2014.

[6] H. Balaga and D. N. Vishwakarma(2015). Artificial Neural Network Based Backup Differential Protection of Generator-Transformer Unit, International Journal of Electronics and Electrical Engineering Vol. 3, No. 6, December 2015.

[7] Nidhi Verma, Kartik Gupta, Sheila Mahapatra(2015). Implementation Of Solid State Relays For Power System Protection, International Journal Of Scientific \& Technology Research Volume 4, Issue 06, ISSN: 2277-8616.

[8] Arathi Premnath, P.Saritha, T.Jarin(2017). SFCL Technology for Generator Protection, Asian Journal of Applied Science and Technology (AJAST), Volume 1, Issue 9, Pages 95-97, October 2017.

[9] M V Sudhakar, Lumesh Kumar Sahu(2017). Simulation of Generator Over-Flux Protectionusing MATLAB, International Journal of Innovative Research in Science, Engineering and Technology (An ISO 3297: 2007 Certified Organization) Website: www.ijirset.com, Vol. 6, Issue 5, May 2017.

[10] Magdi El-Saadawi, Ahmed Hatat(2017). A novel protection scheme for synchronous generator stator windings based on SVM, El-Saadawi and Hatata Protection and Control of Modern Power Systems (2017) 2:24, DOI 10.1186/s41601-017-0057-x.

[11] Mehulkumar D. Devdhariya, Vibhuti R. Adroja, Kajal M. Rafaliya, Prof. Manan M.Desai(2017). Power System Protection with Relay Co-Ordination, IJEDR, Volume 5, Issue 2, ISSN: 23219939.

[12] S.Elango, Dhinesh E, Santhosh kumar K, Sethupathi S, Vivek S (2018). Digital Relay Protection of Generator Transformer in Thermal Power Station Using Microcontroller, International Journal of Intellectual Advancements and Research in Engineering Computations, ISSN:2348-2079, Volume-6 Issue-2, www.ijiarec.com. 
[13] J.K. Wang, and Christian Moya Calderon (2018). A Protection Method in Active Distribution Grids with High Penetration of Renewable Energy Sources, arXiv:1802.00881v1 [math.OC] 3 Feb 2018.

[14] Priti T. Indurkar, S. J. Tikhe(2018). Intelligent Relay for Power System Protection, Journal of Network Communications and Emerging Technologies (JNCET), Volume 8, Issue 3.

[15] Namita Gawas, Darshna Jain, Soham Patil, Rudal Shengale, Rajeev Valunjkar, Priti Singh (2018). Numerical Protection Of Transformer, IOSR Journal of Engineering (IOSRJEN) www.iosrjen.org, ISSN (e): 2250-3021, ISSN (p): 2278-8719, Volume 9, PP 12-14.

[16] Armando Guzmán, Normann Fischer, and Casper Labuschagne(2011). Improvements in Transformer Protection and Control, SEL Journal of Reliable Power, Volume 2, Number 3, September 2011

[17] Ramandeep Kaur Aujla(2008). Theory and applications of protective relays, Department of Electrical and Computer Engineering, The University of Western Ontario London, Ontario, Canada

[18] L.Wei-Jen, G. Jyh-Cherng, L. Ren-Jun, and D. Ponpranod(2002). A physical laboratory for protective relay education, IEEE Transactions on Education, vol. 45, no. 2, pp. 182-186.

[19] B. A. Oza and S. M. Brahma(2005). Development of Power System Protection Laboratory through Senior Design Projects, IEEE Transactions on Power System., vol. 20, no. 2, pp. 532-537.

[20] Ramandeep Kaur Aujla(2008) Generator Stator Protection, under/over voltage, under /over frequency and unbalanced loading, Department of Electrical and Computer Engineering,The University of Western Ontario London, Ontario, Canada.

[21] Khan, M. E., Biswas, A., Islam, M. R.(2013). Restricted earth fault protection with superconducting fault current limiter for $100 \%$ stator winding, International conference on Electrical information and communication technology (EICT), Khulna, pp.1-5.

[22] B. A. Oza and S. M. Brahma (2005). Development of Power System Protection Laboratory through Senior Design Projects, IEEE Transactions on Power System., vol. 20, no. 2, pp. 532-537.

[23] M. R. Zaman and M. A. Rahman (1998). Experimental testing of the artificial neural network based protection of power transformers, IEEE Trans. Power Deliv., vol. 13, no. 2, pp. 510-517.

[24] Z. Moravej and D. Vishwakarma(2003). ANN-Based harmonic restraint differential protection of power transformer, Journal-Institution Eng. India Part EL Electr. Eng. Div., vol. 84, pp. 1-6.

[25] E. C. Segatto and D. V. Coury(2006). A differential relay for power transformers using intelligent tools,
IEEE Trans. Power Syst., vol. 21, no. 3, pp. 11541162.

[26] Prof. V. R. Doifode, Manali V.Aranke, Suyash M.Choudhary,Vividha V.Dhengre, Anmol M.Thawkar(2017). An Overview of Classes \& Grouping in Generator Protection at V. I. P. L. (Nagpur), nternational Conference on Science and Engineering for Sustainable Development (ICSESD2017) (www.jit.org.in), International Journal of Advanced Engineering, Management and Science (IJAEMS) Special Issue-2, https://dx.doi.org/10.24001/ijaems.icsesd2017.93 ISSN : 2454-1311.

[27] Naval Damle, Chandan Kamble(2015). Generator Protection,Stability checking by using Dynamic Testing, International Journal of Research in Advent Technology (E-ISSN: 2321-9637) Special Issue, 1st International Conference on Advent Trends in Engineering, Science and Technology, "ICATEST 2015", 08 March 2015.

[28] Peter Kadar(2013). Application of Optimization Techniques in the Power System Control, Acta Polytechnica Hungarica Vol. 10, No.5.

[29] Ms. Frie Ayalew, Ms. Seada Hussen, Dr. GopiKrishna Pasam(2018). Generator maintenance scheduling in power system by using artificial intelligent techniques: a review, nternational Journal of Engineering Applied Sciences and Technology, Vol. 3, Issue 8, ISSN No. 2455-2143, Pages 1-7, Published Online December 2018 in IJEAST (http://www.ijeast.com).

[30] Ms. Frie Ayalew, Ms. Seada Hussen, Dr. GopiKrishna Pasam (2018). Optimization techniques in power system: A Review, International conference on trends in information, management,engineering and scince (ICTIMES), Malla Reddy College of Engineering,vol 1,Issue 4, ISBN:978-81-939386-3-8, pp:398-403.

[31] Ms. Seada Hussen, Ms. Frie Ayalew, Dr. GopiKrishna Pasam (2018). Review on flexible ac transmission system components in the deregulated power system, International conference on trends in information, management,engineering and scince (ICTIMES),Malla Reddy College of Engineering, vol 1,Issue 4, ISBN:978-81-939386-3-8, pp:293-299.

[32] M. Zielichowski and T. Szlezak(2007), A new digital ground-fault protection system for generatortransformer unit, Electr. Power Syst. Res., vol. 77, no. 10, pp. 1323-1328.

[33] H. A. H. A. Darwish, A.-M. I. A. I. Taalab, and T. A. T. A. Kawady(2001). Development and implementation of an ANN-based fault diagnosis scheme for generator winding protection, IEEE Trans. Power Deliv., vol. 16, no. 2, pp. 208-214.

[34] Jack, L. B., \& Nandi, A. K. (2002). Fault detection using support vector machines and artificial neural 
networks: augmented by Genetic algorithms. Mechanical Systems and Signal Processing, 16(2-3), 373-390.

[35] Hatata, A., Helal, A., El Dessouki, H., El-Saadawi, M., \& Tantawy, M. (2011). Neural network based fault detector and classifier for synchronous generator stator windings. Mansoura Engineering Journal (MEJ), 36(4), E19-E28.

[36] B. Kasztenny, N. Fischer, and H. J. Altuve(2014). Negative-Sequence Differential Protection Principles, Sensitivity, and Security, proceedings of the 41st Annual Western Protective Relay Conference, Spokane, WA, October 2014

[37] Elsamahy M, Faried SO, Sidhu T. (2014). Impact of Midpoint STATCOM on Generator Loss of Excitation Protection. IEEE Transactions on Power Delivery 29(2), 724-732.

[38] Ahmad Rizal Sultan, Mohd Wazir bin Mustafa(2013).Ground Fault Protection Methods of a Generator Stator, echnology University of Malaysia, Faculty of Electrical Engineering, Przegląd Elektrotechniczny, ISSN 0033-2097, R. 89 NR 10/2013.

[39] Tashakori, Hossein(2007). ) Synchronous generator transient behavior and protection under loss of excitation fault, Electronic Teses and Dissertations. 7013.

[40] Manohar Singh; B. K. Panigrahi and A. R. Abhyankar (2012). Combined Optimal Distance to Overcurrent Relay Coordination, International Conference on Power Electronics, Drives and Energy Systems (PEDES), IEEE. 